\title{
The evolution of vertically acquired HCV infection
}

\section{Antonella Versace*, Federica Mignone, Luisella Lazier, Clara Gabiano, Carlo Scolfaro, Alda Alfarano and Pier-Angelo Tovo}

\author{
Address: Department of Paediatrics, University of Turin, Turin, Italy \\ * Corresponding author
}

\author{
from Fourth Dominique Dormont International Conference. Host-Pathogen Interactions in Chronic Infections \\ Paris, France. 13-15 December 2007 \\ Published: 9 April 2008 \\ Retrovirology 2008, 5(SuppI I):PI8 doi:I0.II86/1742-4690-5-SI-PI8
}

This abstract is available from: http://www.retrovirology.com/content/5/SI/PI8

(c) 2008 Versace et al.; licensee BioMed Central Ltd.

\section{Background}

The natural history of vertically acquired HCV infection is unclear, with few studies regarding children prospectively followed from birth at a single centre and mostly with a short follow-up. This limited information casts doubts on the use, in childhood, of antiviral drugs commonly employed in adults with chronic HCV infection.

\section{Materials and methods}

All children with vertically acquired HCV infection who came to our attention and were regularly followed from the first months of life were included in this analysis. One child with double HCV and HIV infection was excluded. HCV associated clinical manifestations, viral genotype, persistence of viremia and HCV antibodies, liver biochemistry (ALT levels, bilirubin, alpha fetoprotein, coagulation parameters), liver ultrasound and other investigations to identify extrahepatic manifestations (e.g. the appearance of auto-antibodies or cryoglobulins, C3 and C4 concentrations) were evaluated.

\section{Results}

Twenty-five children were studied; their median age at the last check was 8.7 years (range 2.0-17.4 years). One child developed hepatomegaly, all the others were asymptomatic. Genotypes 1 and 3 were those most commonly found. Serum HCV-RNA was persistently detected in $68 \%$ $(17 / 25)$ of patients, while viremia was no longer detected in $8(32 \%)$ children in the last several determinations. Anti-HCV antibodies persisted over time in all but one child, who had two positive PCRs in the first months of life and then seroreverted. Most children had increased
ALT levels in the first three years of life (median of 64.0 $\mathrm{mU} / \mathrm{IL}$, range 11-678 mUI/L). Subsequently ALT levels normalised in 12 children (median 22,75 mU/IL, range 15.6-39.5) and remained enhanced in 10 (median 64,2 $\mathrm{mU} / \mathrm{IL}$, range 47.8-92.7). The liver ultrasound was constantly normal in all but two cases, who showed signs of steatosis. Seventeen patients (68\%) developed auto-antibodies: 14 anti-smooth muscle (SMA), 1 anti-nuclear antibody (ANA), 1 anti-liver-kidney microsomal Type 1 (LKM1) antibody, and 1 ANA + LKM1. Cryoglobulins were transiently detected in 7 children (28\%), including one who had mixed type II cryoglobulinemia, though with no concomitant clinical manifestations. C3 and C4 levels were always normal.

\section{Conclusions}

Our findings confirm that vertically acquired HCV infection is usually asymtpomatic in childhood and ALT levels remain within the normal range in a large proportion of cases after the first period of life. However, viremia persists in at least two thirds of children and, of these, a significant percentage develops autoantibodies and/or cryoglobulins. 